\title{
Benefits of Qigong as an integrative and complementary practice for health: a systematic review*
}

\author{
Bruna Francielle Toneti ${ }^{1,2}$ \\ (D) https://orcid.org/0000-0002-8565-4905 \\ Rafael Fernando Mendes Barbosa ${ }^{1}$ \\ (iD) https://orcid.org/0000-0003-2063-5145 \\ Leandro Yukio Mano 3,4 \\ (D) https://orcid.org/0000-0003-2215-0133 \\ Luana Okino Sawada ${ }^{5}$ \\ (D) https://orcid.org/0000-0001-8168-2995 \\ Igor Goulart de Oliveira ${ }^{6}$ \\ (i) https://orcid.org/0000-0001-9810-8842 \\ Namie Okino Sawada ${ }^{7}$ \\ (D) https://orcid.org/0000-0002-1874-3481
}

\footnotetext{
* Paper extracted from master's thesis "Development and validation of digital technologies directed to the teaching of an integrative and complementary health practice", presented to Universidade de São Paulo, Escola de Enfermagem de Ribeirão Preto, PAHO/WHO Collaborating Centre at the Nursing Research Development, Ribeirão Preto, SP, Brazil.

1 Universidade de São Paulo, Escola de Enfermagem de Ribeirão Preto, PAHO/WHO Collaborating Centre at the Nursing Research Development, Ribeirão Preto, SP, Brazil.

2 Scholarship holder at the Coordenação de Aperfeiçoamento de Pessoal de Nível Superior (CAPES), Brazil.

3 Universidade de São Paulo, Instituto de Ciências Matemáticas e de Computação, São Carlos, SP, Brazil.

${ }^{4}$ Scholarship holder at the Fundação de Amparo à Pesquisa do Estado de São Paulo (FAPESP), Brazil.

${ }^{5}$ School of Computing and Information Science, Florida International University, Miami, FL, United States of America.

${ }^{6}$ Universidade Estadual do Norte do Paraná, Centro de Ciências Tecnológicas, Bandeirantes, PR, Brazil.

Universidade Federal de Alfenas, Escola de Enfermagem, Alfenas, MG, Brazil.
}

Objective: to analyze, in the literature, evidence about the benefits of the integrative and complementary practice of Qigong with regard to the health of adults and the elderly. Method: a systematic review by searching for studies in the PubMed, CINAHL, LILACS, EMBASE and Cochrane Library databases. Randomized and non-randomized clinical trials were included; in Portuguese, English and Spanish; from 2008 to 2018. The Preferred Reporting Items for Systematic Reviews and MetaAnalyses strategy was adopted, as well as the recommendation of the Cochrane Collaboration for assessing the risk of bias in the clinical trials analyzed. Results: 28 studies were selected that indicated the benefit of the practice to the target audience, which can be used for numerous health conditions, such as: cancer; fibromyalgia; Parkinson's disease; Chronic Obstructive Pulmonary Disease; Burnout; stress; social isolation; chronic low back pain; cervical pain; buzz; osteoarthritis; fatigue; depression; and cardiovascular diseases. However, there was a great risk of bias in terms of the blinding of the research studies. Conclusion: the practice of Qigong produces positive results on health, mainly in the medium and long term. This study contributes to the advancement in the use of integrative and complementary practices in nursing, since it brings together the scientific production in the area from the best research results available.

Descriptors: Complementary Therapies; Medicine, Chinese Traditional; Qigong; Systematic Review; Evidence-Based Practice; Nursing.

\section{How to cite this article}

Toneti BF, Barbosa RFM, Mano LY, Sawada LO, Oliveira IG, Sawada NO. Benefits of Qigong as an integrative and complementary practice for health: a systematic review. Rev. Latino-Am. Enfermagem. 2020;28:e3317. [Access ‘_十_ †]; Available in: DOI: http://dx.doi.org/10.1590/1518-8345.3718.3317. 


\section{Introduction}

Also known as alternative and/or complementary practices (Práticas Integrativas e Complementares, PICs), integrative therapies are aimed at achieving physical and mental well-being and are able to alleviate symptoms arising from health conditions and conventional treatments ${ }^{(1-2)}$.

In 2006, in Brazil, PICs were recognized, following the publication of the National Policy on Integrative and Complementary Practices (Política Nacional de Práticas Integrativas e Complementares, PNPIC), by Ordinance No. 971, including the following in the Unified Health System (Sistema Único de Saúde, SUS): Traditional Chinese Medicine (TCM)/Acupuncture; Homeopathy; Medicinal Plants, Phytotherapy; Anthroposophical Medicine; and Crenotherapy-Social Thermalism. Eleven years later, with Ordinance No. 849, others were added: Art Therapy, Ayurveda, Biodance, Circular Dance, Meditation, Music Therapy, Naturopathy, Osteopathy, Chiropractic, Reflexotherapy, Reiki, Shantala, Integrative Community Therapy, and Yoga(3-4).

Recently, in 2018, by Ordinance No. 702, the following were added to the system: Aromatherapy, Apitherapy, Bioenergetics, Family Constellation, Chromotherapy, Geotherapy, Hypnotherapy, Laying on of Hands, Ozone Therapy, and Flower Therapy(5). The fact that PICs have their demand increased, as well as their insertion in the SUS, points to the beginning of a movement in Brazil in the search for qualifying the form of health care offered to the population, which is gradually more comprehensive, resolutive, and universal(1).

Qigong is a TCM PIC that meets this perspective of health care. And, as already discussed, it is a practice with a high level of recognition for its positive health results. During the process, there is an improvement in the transport of energy and blood through the established body-mind relationship, which influences the blood, the essence, body fluids, and the mind, essential to the human being. In this way, it is possible to adjust and harmonize the flows of $Q i$ and the Yin-Yang of the body, therefore promoting health(6).

A study in the area has progressively explored the results of this therapy in different target audiences, for example, people with advanced age and others with chronic health conditions that are not susceptible to transmission, in order to understand its influence in terms of health ${ }^{(6)}$. However, more evaluations, from studies with recognized methods, are necessary with regard to the physiology involved in the results of therapy, so that it is possible to develop what is known in the area regarding its relationship with the health of practitioners, a reason that encouraged the development of the present study.

Practices that develop both physical and mental conditions and Quality of Life (QoL), such as the PICs, are the foundation for the search for quality nursing care, carried out during the sharing of knowledge between professionals and users of health. In this sense, there is an appreciation of their active participation in this process( $^{(2)}$.

The fact that nurses use PICs is related to a humanizing movement for the integration of care, which covers its dissemination, as well as the act of making them legitimate in this context. Although the literature presents solid evidence, there is little use of these practices by professionals in the area and patients ${ }^{(1-2)}$.

Therefore, in order to build a scientific contribution, in addition to optimizing the action of nursing in both care and health production, research that explores the results of the PICs, such as Qigong, with a focus on those related to nursing, are essential. That said, the objective of this systematic review was to analyze, in the literature, evidence about the benefits of the integrative and complementary practice of Qigong with regard to the health of adults and the elderly.

\section{Method}

The literature Systematic Review (SR) method makes it possible to gather, analyze, and synthesize scientific productions regarding a certain clinical issue, so that it is possible to understand, discuss, and establish clinical actions based on evidence ${ }^{(7)}$.

The methodological trajectory followed was based on the Preferred Reporting Items for Systematic Reviews and Meta-Analyses (PRISMA), through its checklist of items and flow chart for the development of a $\mathrm{SR}^{(8-9)}$.

In order to construct the research question of this SR, the PICO strategy was used: Patient/Population/ Problem of interest $(P)$ : adults and the elderly; Intervention/Area of Interest (I): practice of Qigong; Comparison (C): not applicable; and Outcomes/ Results (O): benefits of practicing Qigong to health. With it, it is possible to identify keywords on the subject. The strategy is essential with regard to the development of the search strategy for relevant primary studies in databases $^{(9)}$.

Thus, the following question was obtained: Does the practice of Qigong have beneficial effects on the health of adults and the elderly? The research of the primary studies, carried out from the descriptors presented below, took place in the following databases: National Library of Medicine National Institutes of Health (PubMed), Cumulative Index to Nursing and 
Allied Health Literature (CINAHL); Latin American and Caribbean Health Sciences Literature (Literatura Latino-Americana e do Caribe em Ciências da Saúde, LILACS); Excerpta Medica Database (EMBASE); and Cochrane Controlled Register of Trials (CENTRAL) - Cochrane Library.
For that, descriptors were used, as well as synonyms, in agreement with the Health Sciences Descriptors (Descritores em Ciências da Saúde, DeCS), the Medical Subject Headings (MeSH) and the Emtree from Elsevier Life Science (Emtree), as shown in Figure 1.

\begin{tabular}{|c|c|c|c|c|}
\hline Database & \multicolumn{2}{|r|}{ Controlled descriptors } & Not controlled & Search strategy \\
\hline $\begin{array}{l}\text { PubMed } \\
\text { (MeSH) }\end{array}$ & \multirow{3}{*}{\multicolumn{2}{|c|}{$\begin{array}{c}\text { Adult } \\
\text { Young Adult } \\
\text { Aged } \\
\text { Qigong } \\
\text { Treatment Outcome } \\
\text { Outcome Assessment } \\
\text { (Health Care) }\end{array}$}} & \multirow{5}{*}{$\begin{array}{l}\text { Older Adults } \\
\text { Qi Gong } \\
\text { Ch'i Kung }\end{array}$} & \multirow{4}{*}{$\begin{array}{c}(((((\text { Adult) OR (Young Adult) OR } \\
\text { (Older Adults) OR (Aged) OR } \\
\text { (Elderly)))) AND (((Qigong) OR } \\
\text { (Qi Gong) OR (Ch'i Kung)))) AND } \\
(((\text { Treatment Outcome) OR (Outcome } \\
\text { Assessment (Health Care)))) }\end{array}$} \\
\hline $\begin{array}{l}\text { CINAHL } \\
\text { (MeSH) }\end{array}$ & & & & \\
\hline $\begin{array}{c}\text { Cochrane Central } \\
\quad(\mathrm{MeSH})\end{array}$ & & & & \\
\hline $\begin{array}{l}\text { EMBASE } \\
\text { (Emtree) }\end{array}$ & $\begin{array}{l}\text { Adult } \\
\text { Young Adult } \\
\text { Aged } \\
\text { Qigong }\end{array}$ & $\begin{array}{l}\text { Treatment Outcome } \\
\text { Outcome Assessment } \\
\text { (Health Care) }\end{array}$ & & \\
\hline $\begin{array}{l}\text { LILACS } \\
\text { (DeCS) }\end{array}$ & $\begin{array}{l}\text { Adult } \\
\text { Adulto } \\
\text { Adulto } \\
\text { Young Adult } \\
\text { Adulto Joven } \\
\text { Adulto Jovem } \\
\text { Aged } \\
\text { Anciano } \\
\text { Idoso }\end{array}$ & $\begin{array}{c}\text { Qigong } \\
\text { Treatment Outcome } \\
\text { Resultado del Tratamiento } \\
\text { Resultado do tratamento } \\
\text { Outcome Assessment } \\
\text { (Health Care) } \\
\text { Evaluación de Resultado (Atención de Salud) } \\
\text { Avaliação de Resultado (Cuidados de Saúde) }\end{array}$ & & $\begin{array}{c}\text { (tw:((Adult) OR (Adulto) OR (Adulto) } \\
\text { OR (Young Adult) OR (Adulto Joven) } \\
\text { OR (Adulto Jovem) OR (Aged) } \\
\text { OR (Anciano) OR (Idoso))) AND } \\
\text { (tw:((Qigong) OR (Qi Gong) OR } \\
\text { (Ch'i Kung))) AND (tw:((Outcome } \\
\text { Assessment (Health Care)) OR } \\
\text { (Evaluación de Resultado (Atención } \\
\text { de Salud)) OR (Avaliação de } \\
\text { Resultado (Cuidados de Saúde)))) }\end{array}$ \\
\hline
\end{tabular}

Figure 1 - Search strategy for the primary studies of the systematic review. Ribeirão Preto, SP, Brazil, 2019

The following were adopted as inclusion criteria: randomized and non-randomized clinical trials related to the use of Qigong by adults and the elderly; which answer the research question; written in Portuguese, English or Spanish; beginning in January 2008 and ending in December 2018 (considering this as an important historical period for the recognition of Integrative and Complementary Practices [PICs] as the Qigong scientific and political circles); available on the mentioned bases. The exclusion criteria adopted were the following: not selecting research studies related to medical Qigong (external); which did not discuss assessing the effects of Qigong or did not present a correct definition of it; and which presented only clinical trial protocols, without obtaining results.

The search was carried out concomitantly in November 2018, through the five databases mentioned. When crossing the descriptors, 334 articles were found. In order to manage the research studies, the Rayyan QCRI ${ }^{\circledR}$ and EndNote Web ${ }^{\circledR}$ software were used. The same programs were used to export, organize, and filter studies with respect to duplication in the databases. The studies were pre-selected when reading titles and abstracts and, finally, they were selected for this review through complete reading in order to include them in the sample. Pre-selection was also carried out by reading the title and summary and, finally, selecting the studies for the final review by reading them in full for inclusion in the sample.

Data extraction was performed by two reviewers, independently. The recommendations of the Consolidated Standards of Reporting Trials(10) were adopted for the careful reading of each included clinical trial, and a summary table was elaborated with the following information for the full analysis: identification (title and abstract); introduction (scientific basis, justification and objectives); method (type of study, inclusion and exclusion criteria of participants, interventions performed, hypotheses, sample size, randomization, blinding and statistical analysis); results (recruitment, baseline data, numbers analyzed, estimates, auxiliary analyzes and unwanted effects and damage in the groups analyzed); discussion (limitations, generalization and interpretation of results); conclusion; and protocol records. Both the research design and the level of evidence of the articles were carried out, so that it was possible to classify them according to the evidence hierarchy ${ }^{(11)}$. 
The critical evaluation of the studies was carried out based on the recommendation of the Cochrane Collaboration(12) for assessing the risk of clinical trial bias. It is a tool that allows for the assessment of several types of bias found in clinical trials, being organized into seven domains, with three categories each, namely: high risk of bias, low risk of bias, and uncertain risk of bias. Such an instrument was chosen because it was necessary to analyze the level of the research methodology found in the SR, so that the results from the scientific evidence in the literature were reliable.

\section{Results}

28 studies were selected that were compatible with the inclusion criteria adopted for this SR, and studies were not added from the review of the references of this selected sample, as shown in Figure 2.

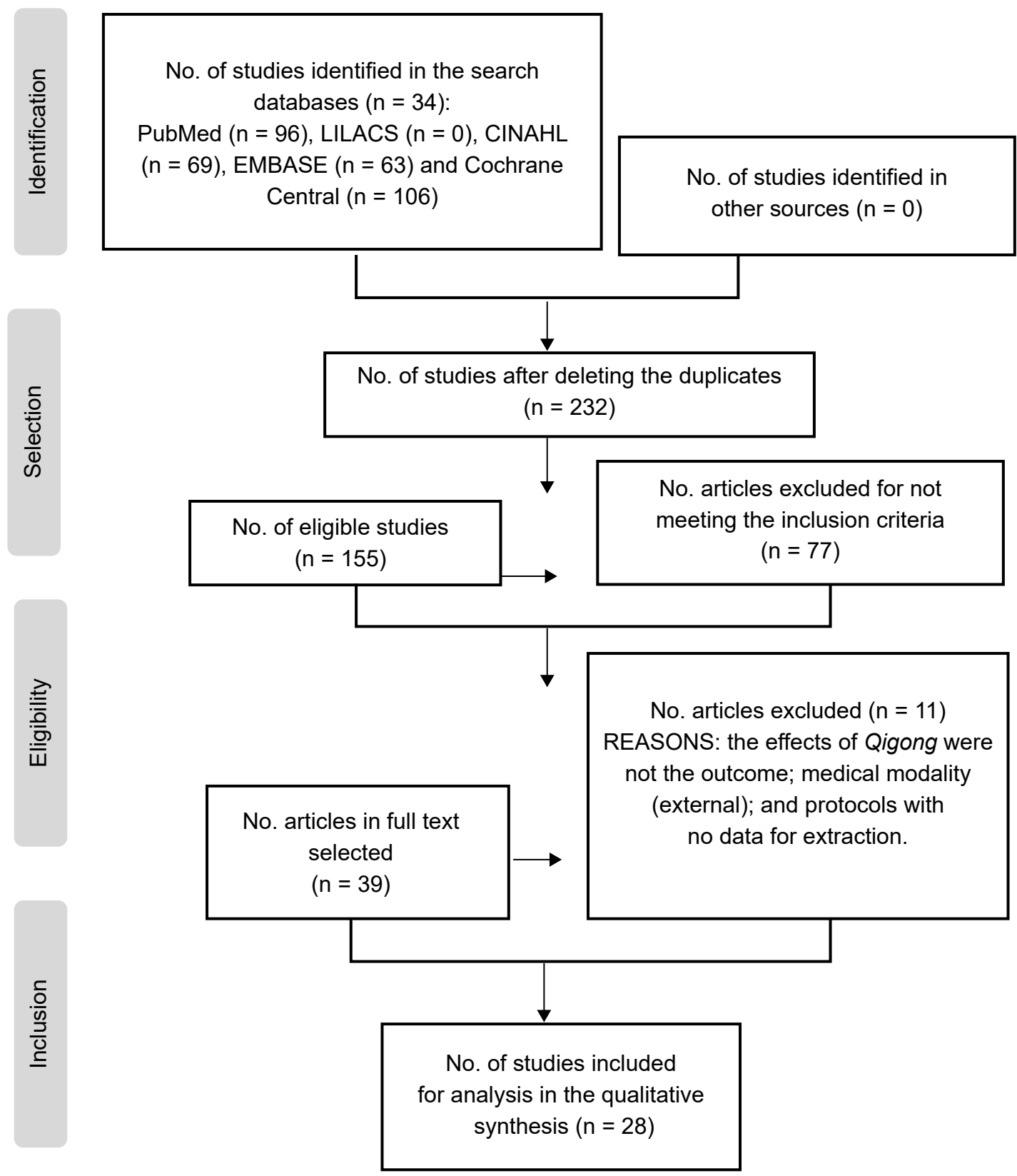

Figure 2 - Flow of study selection, according to the adaptation of PRISMA(8). Ribeirão Preto, SP, Brazil, 2019

Regarding the main authorship of the articles, $13(46.4 \%)$ were physicians, eight (28.6\%) were nurses, two $(7.1 \%)$ were psychologists, two $(7.1 \%)$ were occupational therapists, one $(3.6 \%)$ was a pharmacist, one (3.6\%) was a physical educator, and one (3.6\%) was a physical therapist.
It was also noted that $15(53.6 \%)$ of the studies were carried out in China, five (17.9\%) in Germany, three $(10.7 \%)$ in the United States, two (7.1\%) in Sweden, two (7.1\%) in Korea, and one (3.6\%) in Thailand. Figure 3, presents the description of the studies analyzed in the SR. 


\begin{tabular}{|c|c|c|}
\hline Study & Year & Title \\
\hline E1 & 2016 & Exploratory outcome assessment of Qigong/Tai Chi Easy on breast cancer survivor ${ }^{133}$. \\
\hline E2 & 2016 & Effect of health Baduanjin Qigong for mild to moderate Parkinson's disease ${ }^{(14)}$. \\
\hline E3 & 2015 & Randomized controlled trial of Qigong/Tai Chi Easy on cancer-related fatigue in breast cancer ${ }^{(15)}$. \\
\hline E4 & 2016 & Qigong or Yoga Versus No Intervention in Older Adults With Chronic Low Back Pain: a Randomized Controlled Tria/(16). \\
\hline E5 & 2015 & Qigong versus exercise therapy for chronic low back pain in adults: a randomized controlled non-inferiority trial(17). \\
\hline E6 & 2012 & Therapeutic Effects of Qigong in Patients with COPD: a Randomized Controlled Tria/(18). \\
\hline E7 & 2009 & Effects of Qigong in patients with burnout: a randomized controlled tria/(19). \\
\hline E8 & 2011 & Functional and Psychosocial Effects of Health Qigong in Patients with COPD: a Randomized Controlled Trial/20). \\
\hline E9 & 2016 & $\begin{array}{l}\text { Effects of Qigong Exercise on Biomarkers and Mental and Physical Health in Adults With at Least One Risk Factor for } \\
\text { Coronary Artery Disease(21). }\end{array}$ \\
\hline E10 & 2013 & $\begin{array}{l}\text { Effects of a Brief Qigong-based Stress Reduction Program (BQSRP) in a distressed Korean population: a randomized } \\
\text { tria/(22). }\end{array}$ \\
\hline E11 & 2013 & Psycho-physical and neurophysiological effects of qigong on depressed elders with chronic illness ${ }^{(23)}$. \\
\hline E12 & 2012 & A randomized controlled trial of qigong for fibromyalgia ${ }^{(24)}$. \\
\hline E13 & 2012 & $\begin{array}{l}\text { A Randomized Controlled Trial of Qigong Exercise on Fatigue Symptoms, Functioning, and Telomerase Activity in Persons } \\
\text { with Chronic Fatigue or Chronic Fatigue Syndrome }{ }^{(25)} \text {. }\end{array}$ \\
\hline E14 & 2011 & Tai chi Qigong improves lung functions and activity tolerance in COPD clients: a single blind, randomized controlled trial(26). \\
\hline E15 & 2011 & Qigong Versus Exercise Versus No Therapy for Patients With Chronic Neck Pain: a randomized controlled trial(27). \\
\hline E16 & 2010 & Qigong for the treatment of tinnitus: a prospective randomized controlled study ${ }^{(28)}$. \\
\hline E17 & 2009 & Qigong and exercise therapy for elderly patients with chronic neck pain (QIBANE): a randomized controlled study ${ }^{(29)}$. \\
\hline E18 & 2009 & Tai Chi Qigong for the quality of life of patients with knee osteoarthritis: a pilot, randomized, waiting list controlled trial(30). \\
\hline E19 & 2008 & The effect of Qigong on Fibromyalgia (FMS): a controlled randomized study ${ }^{(31)}$. \\
\hline E20 & 2017 & Qigong/tai chi for sleep and fatigue in prostate cancer patients undergoing radiotherapy: a randomized controlled trial/32). \\
\hline E21 & 2015 & $\begin{array}{l}\text { The Effects of a 6-Month Tai Chi Qigong Training Program on Temporomandibular, Cervical, and Shoulder Joint Mobility } \\
\text { and Sleep Problems in Nasopharyngeal Cancer Survivors }{ }^{(33)} \text {. }\end{array}$ \\
\hline E22 & 2016 & $\begin{array}{l}\text { A randomized controlled trial of qigong on fatigue and sleep quality for non-Hodgkin's lymphoma patients undergoing } \\
\text { chemotherapy }{ }^{(34)} \text {. }\end{array}$ \\
\hline E23 & 2013 & The sustaining effects of Tai chi Qigong on physiological health for COPD patients: a randomized controlled trial(35). \\
\hline E24 & 2017 & $\begin{array}{l}\text { Effects of tai chi qigong on psychosocial well-being among hidden elderly, using elderly neighborhood volunteer approach: a } \\
\text { pilot randomized controlled tria/(36). }\end{array}$ \\
\hline E25 & 2017 & $\begin{array}{l}\text { A nurse facilitated mind-body interactive exercise (Chan-Chuang qigong) improves the health status of non-Hodgkin } \\
\text { lymphoma patients receiving chemotherapy: Randomised controlled trial(137). }\end{array}$ \\
\hline E26 & 2017 & $\begin{array}{l}\text { The efficacy of Guolin-Qigong on the body-mind health of Chinese women with breast cancer: a randomized controlled } \\
\text { trial(38). }\end{array}$ \\
\hline E27 & 2018 & Effects of Qigong practice in office workers with chronic non-specific low back pain: a randomized control trial(39). \\
\hline E28 & 2014 & Effect of qigong training on fatigue in haemodialysis patients: a non-randomized controlled trial(40). \\
\hline
\end{tabular}

Figure 3 - Description of the studies included in the systematic review, according to year of publication and titles. Ribeirão Preto, SP, Brazil, 2019

All the articles submitted for analysis were published in English, and 21 of them were in different journals with a predominance $(n=24)$ of medical journals. Only one was not randomized, although all were evaluated with level of evidence of II, considered strong, according to the theoretical framework adopted(11).

The works were critically evaluated, according to Figure 4, with the risk of bias assessment, in accordance with the criteria of the Cochrane Collaboration(12) in order to determine the reliability of the results.

In order to fulfill the objective of this SR and to conduct a comparison between the data obtained and the literature, the articles were organized into five thematic categories. The first was established regarding health prevention associated with therapy, in which E9(21), conducted with adults diagnosed with risk of Coronary 
Artery Disease $(C A D)(n=139)$ and with a mean age of 62 years old, showed an improvement in perceived mental and physical health $(p<0.001)$, and also in the amount of body fat $(p<0.001)$ compared to the control group. Also, the intervention (12 weeks) showed important results in lipid profiles, with significantly lower mean levels; however, not with regard to protein (hs-CRP), glycated hemoglobin (HbA1c), and fasting plasma sugar ${ }^{(21)}$.

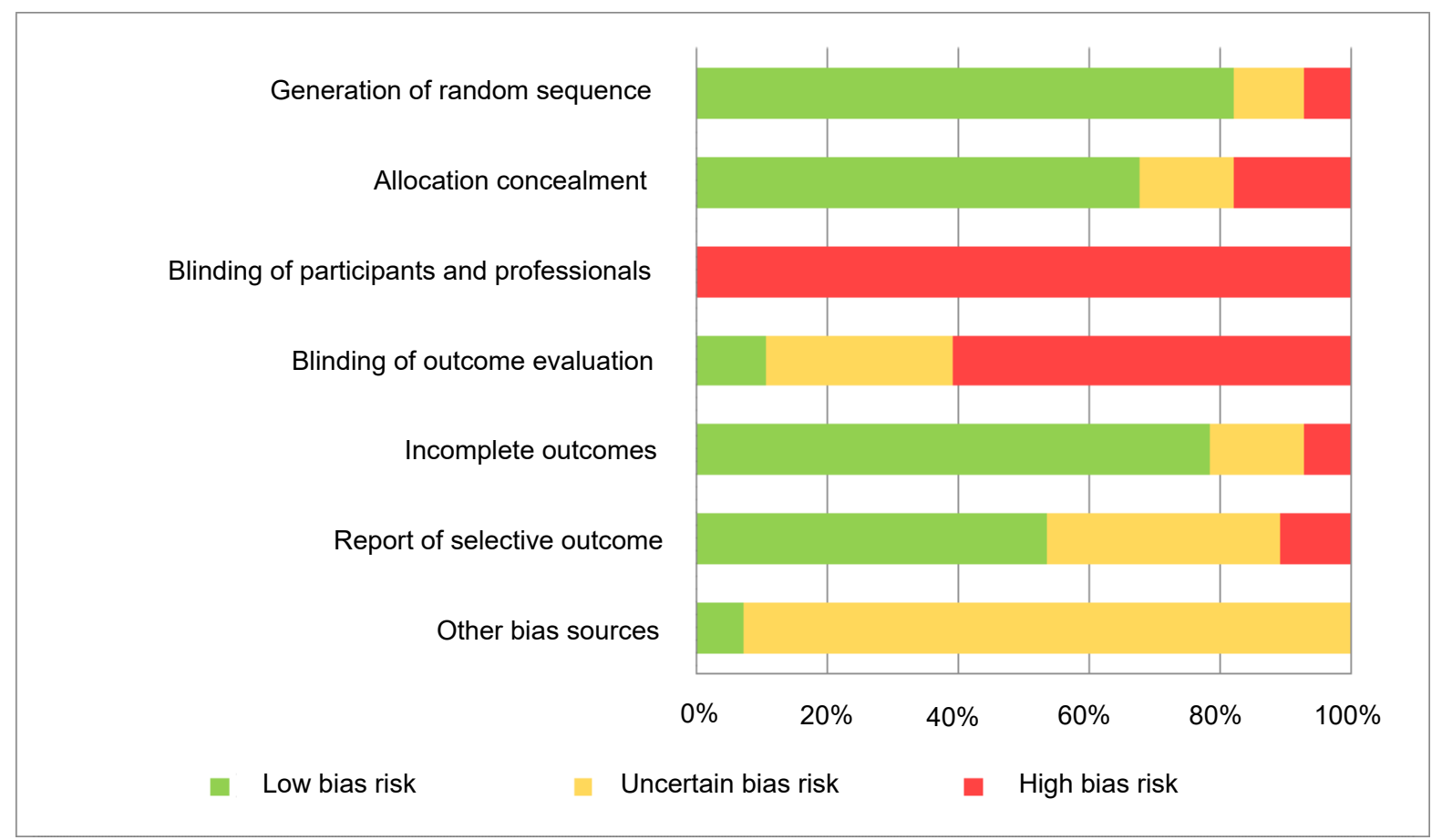

Figure 4 - Bias risk assessment of the studies included in the systematic review, according to the Cochrane Collaboration assessment tool(12). Ribeirão Preto, SP, Brazil, 2019

The second thematic category dealt with the psychosocial effects caused by Qigong in three studies (E10, E11 and E24). E10(22) held a Qigong program (4 weeks) in stressed subjects $(n=50)$ with a mean age of 38 years old showing that, compared to the control group, the intervention group had significantly greater reductions in the perceived stress scale scores $(p=0.0006)$, anxiety state $(p=0.0028)$, anxiety trait $(p<0.0001)$, personality subscales $(p=0.0321)$, symptoms ( $p=0.0196)$ for rabies syndrome, as well as a significantly greater increase in the World Health Organization (WHO) QoL scores ( $p<0.05$ ). However, the salivary cortisol indexes did not change ${ }^{(22)}$.

E11(23), study of Qigong (12 weeks) in depressed elderly people with chronic diseases $(n=38)$ and with a mean age of 80 years old, revealed that the intervention group showed a significant reduction in the depressive symptoms ( $p<0.025)$, improved self-efficacy ( $p=0.050)$, improved self-concept of physical well-being $(p<0.025)$, and increased physical strength $(p=0.034)$. In addition, a lower level of salivary cortisol $(p<0.008)$ was found in the referred group ${ }^{(23)}$.

E24(36), conducted with socially isolated elderly individuals ( $n=46)$ with an average age of 77 years old, showed that Tai Chi/Qigong (3 months) significantly improved the loneliness scale ( $p=0.033)$, as well as the satisfaction component of the social support questionnaire ( $p=0.044$ ) when compared to the people in the control group. Another important fact is that $82 \%$ of the participants reported that they would continue the exercises, while nine reported that they extended their friendship circle, which indicates that the majority liked to practice Tai Chi/Qigong(36).

The third thematic category referred to the analgesic effects related to the practice of Qigong, in which five studies were analyzed (E4, E5, E15, E17 and $E 27)$. E4 ${ }^{(16)}$, conducted with elderly people with low back pain $(n=176)$ with a mean age of 72 years old, showed no statistically significant distinctions in the groups regarding changes in the degree of low back pain during the survey (Qigong $\mathrm{x}$ Yoga, $\mathrm{p}=0.18$, and Qigong $x$ Control, $\mathrm{p}=0.12$ ). However, there was satisfaction with the Qigong therapy (7.9) and Yoga (7.8) and greater chances of recommending it to other individuals ${ }^{(16)}$.

E5 ${ }^{(17)}$ investigated the therapy (3 months) in patients with chronic low back pain $(n=123)$ with a mean age of 46 years old, revealing that there was no statistical confirmation of non-inferiority ( $p=0.204)$ - taking into account the margin of non-inferiority of 
$5 \mathrm{~mm}$ considered by the research in question in the mean intensity of low back pain - from the Qigong group ( $n=64 ; 34.8 \mathrm{~mm}$ ) when compared to the control group $(n=63 ; 33.1 \mathrm{~mm})$, with the practice of stretching and relaxing for chronic low back pain. The distinction found was only the fact that the Qigong group adhered more in guided classes (67.2\%), as well as those made at home $(72 \%)^{(17)}$.

E15(27) revealed that Qigong (6 months), in adults presenting chronic pain in the cervical region $(n=122)$ with a mean age of 45 years old, showed a significant difference with the control group with regard to the degree of pain $(p=0.002)$. The secondary results submitted to evaluation (neck pain, lack of capacity, and QoL) demonstrated the benefits of Qigong when compared to the control group, similarly when it comes to conventional exercises(27). As for $\mathrm{E} 17^{(29)}$, conducted with elderly people presenting chronic pain in the cervical region ( $n=93$ ) with a mean age of 75 years old, regarding pain, lack of capacity, and QoL, no significant distinctions were identified when comparing the Qigong (3 months) and control ( $p=0.099$ ) groups, as well as those with conventional exercise practices $(p=0.699)^{(29)}$.

Finally, E27(39), conducted with adults reporting chronic and non-specific pain in the lower back and working in offices ( $n=62$ ) with a mean age of 35 years old, showed an important reduction in the degree of pain and functional disability in the lower back $(p<0.022)$ for people in the Qigong group (6 weeks). In addition, important improvements were identified with regard to the degree of pain $(p<0.001)$, functional impairment of the back region $(p<0.001)$, range of motion $(p<0.001)$, muscle strength $(p<0.001)$, heart rate $(p<0.001)$, and mental status ( $p=0.005)$, in addition to better overall satisfaction with the practice $(p<0.001)$ in the intervention group ${ }^{(39)}$.

The fourth thematic category referred to the effects of the therapy in the area of oncology, in which seven studies (E1, E3, E20, E21, E22, E25 and E26) were grouped. $E 1^{(13)}$, conducted with 87 individuals who survived breast cancer, with a mean age of 59 years old, pointed to subsequent physical and psychological benefits (12 weeks), as well as an important increase in the level of physical activity and cognitive function $(p<0.001)$. There was also a reduction in body weight by the BMI $[-0.66(p=0.048)]$ when compared to the other exercise group ${ }^{(13)}$.

E3 ${ }^{(15)}$ tested an intervention (12 weeks) with Easy Qigong/Tai Chi versus Sham Qigong in relation to fatigue, depression, and sleep quality of people who survive breast cancer $(n=87)$ with a mean age of 58 years old. In this study, an important reduction in fatigue was found in the Easy Qigong/Tai Chi group ( $p=0.005$ ) compared to the other group, maintained throughout the 90 days of practice ( $p=0.024)$. In addition, there was an improvement in depression and sleep in both interventions $(p<0.05)^{(15)}$.

As for $E 20^{(32)}$, which evaluated men with prostate cancer ( $n=50)$ undergoing radiotherapy treatment with a mean age of 64 years old, it was noted that the group that practiced Qigong during the treatment described longer nights of sleep ( $p=0.05)$ when compared to the control groups and to those who performed milder activities; however, at the end of radiotherapy, this no longer occurred(32).

On the other hand, E21(33), involving people who survived nasopharyngeal neoplasia $(n=52)$ and aged 58 years old, brought about positive results ( 6 months). The range of motion in the cervical region was improved $(p<0.008)$, and the mobility of the shoulders and temporomandibular joints did not change ( $p>0.008$ ). Worsening of the shoulder range of motion and of the ability to open the mouth was gradually identified in the control group $(p<0.008)$. Regarding sleep difficulties, there were improvements for the intervention group ( $p<0.008$ ), related to the development of the range of motion in the cervical region $(p<0.05)^{(33)}$.

$E 22^{(34)}$ assessed people affected by non-Hodgkin's lymphoma undergoing chemotherapy $(n=102)$ with a mean age of 59 years old, also showing an important decrease in fatigue and an increase in sleep quality ( $p<0.001$ ) for Qigong (12 weeks), provided there is a considerable practice period ${ }^{(34)}$. In this sense, E25(37), conducted with patients affected by the same disease $(n=96)$ with a mean age of 60 years old and submitted to the first cycle of chemotherapy treatment, also revealed an important improvement in the level of fatigue $(p<0.001)$ for the intervention group, in addition to white blood cells $(p<0.001)$, hemoglobin $(p=0.002)$, and sleep quality $(p<0.001)^{(37)}$.

In addition, E2 ${ }^{(38)}$, conducted with participants rehabilitating from breast cancer $(n=158)$ with a mean age of 50 years old, there were benefits for emotional $(p<0.01)$ and specific $(p<0.01)$ wellbeing with regard to QoL submitted to evaluation and comparison with the control group for Qigong (24 weeks). There were benefits regarding anxiety $(p<0.01)$ for the intervention group. The control group had benefits for depression $(p<0.05)$. However, no significant distinction was identified between them. Both groups showed immunity benefits; however, in the Qigong one, it was more developed in the degrees of tumoral necrosis-alpha (TNF-a) $(p<0.05)$ compared to the control group ${ }^{(38)}$.

Finally, the fifth thematic category grouped twelve studies (E2, E6, E7, E8, E12, E13, E14, E16, 
E18, E19, E23 and E28) regarding the use of Qigong for health rehabilitation. E2 ${ }^{(14)}$, conducted with patients with Parkinson's Disease ( $n=89$ ), belonging to the 67-year-old age group, showed that the group practicing Baduanjin Qigong (6 months) presented important developments in sleep $(p=0.029)$, functional mobility $(p=0.041)$, and 6 -minute walk test $(p=0.042)$ when compared to the control group. In addition, walking speed ( $p=0.011)$ was increased ${ }^{(14)}$.

E6 (18), conducted with patients with Chronic Obstructive Pulmonary Disease (COPD) $(n=118)$ with a mean age of 62 years old, revealed that, even without being related to the stage of the disease, both the group that practiced Qigong conventional pulmonary rehabilitation activities improved with respect to the 6-minute walk test and QoL scores when compared to the control group. More precisely, those who practiced Qigong improved in decreasing acute exacerbation of COPD stage I, as well as the related complications, in addition to maintaining the stability of the TNF-a factor level for people with COPD stage $\mathrm{II}^{(18)}$.

As for $E 7^{(19)}$, conducted with participants with Burnout ( $n=68$ ) with a mean age of 44 years old, the results did not obtain statistically relevant distinctions in relation to the groups considered (12 weeks), since both had benefits in reducing the degrees of Burnout, fatigue, anxiety, and depression through Qigong(19).

Still with COPD participants $(n=52)$ with a mean age of 73 years, $E 8^{(20)}$ showed evidence for the development of functional capacity and QoL in all of its subscales in the group that practiced Qigong, while the other group showed signs of worsening QoL in four (general health, mental health, fatigue, and emotional)(20).

Fibromyalgia was assessed in $\mathrm{E}_{12}{ }^{(24)}(\mathrm{n}=89)$, in adults with a mean age of 52 years old, where the group that practiced Qigong (6 months) presented important pain-related benefits ( 2 months: $p<0.0001$; 4 months: $p=0.0002$; and 6 months: $p=0.02)$; impact of fibromyalgia ( 2 months: $p<0.0001$; 4 months: $\mathrm{p}=0.005$; and 6 months: $\mathrm{p}=0.02$ ); sleep quality ( 2 months: $p=0.004 ; 4$ months: $p=0.0007$; and 6 months: $p=0.01$ ); physical function ( 2 months: $\mathrm{p}=0.001 ; 4$ months: $\mathrm{p}=0.009 ;$ and 6 months: $p=0.02$ ); and mental function ( 2 months: $p=0.001$; 4 months: $p=0.05$; and 6 months: $p=0.35$ ) in the QoL domains submitted to evaluation, compared to the control group (24).

E13(25), conducted with people showing chronic fatigue ( $n=52$ ) with a mean age of 42 years old, showed the effectiveness of the intervention (4 months) with important benefits compared to the control group regarding the total fatigue score $(p<0.05)$, physical fatigue $(p<0.01)$, mental fatigue $(p<0.05)$, and mental functioning $(p=0.001)$. Also, telomerase in the group with Qigong practitioners was statistically relevant compared to the control group $(p<0.05)^{(25)}$.

Regarding $E 14^{(26)}$, conducted with individuals with COPD $(n=206)$ with a mean age of 73 years old, improvements similar to other studies were found in the Qigong group (3 months) with regard to vital capacity ( $p=0.002)$, forced expiratory volume in 1 second $(p<0.001)$, and exacerbation rate $(p=0.006)$. This was not evidenced in the conventional exercise group. Worsening of lung function was noted for the control group (26).

Therapy was also assessed in $\mathrm{E}_{16}{ }^{(28)}$, conducted with individuals with tinnitus $(n=71)$ with a mean age of 45 years old, revealing that Qigong (5 weeks) improved tinnitus ( $p<0.0001)$. Also, it is possible to consider that the intervention is potentially beneficial for the treatment of this condition given the great satisfaction of people with the therapy, as well as the stability of its effects ( 3 months) ${ }^{(28)}$. In $E 18^{(30)}$, conducted with people affected by symptomatic osteoarthritis with radiological changes in the knee joint ( $n=44)$, with a mean age of 69 years old, the therapy showed statistically significant benefits for QoL in relation to the control group ( $p=0.010$ ), as well as in the 6 -minute walk test $(p=0.005)^{(30)}$.

Individuals with Fibromyalgia Syndrome (FMS) $(n=57)$, with a mean age of 69 years old, were also studied in $E 19^{(31)}$, with an important decrease in pain $(p<0.0001)$, in addition to less inconvenience reported due to the condition $(p<0.0001)$ and better ability to keep it under control ( $p<0.01$ ) with therapy. Similarly, the group with people who practiced Qigong (7 weeks) reported a significant decrease in anxiety in relation to the control group ( $p<0.01$ ), in addition to a benefit in relation to QoL $(p<0.01)^{(31)}$.

Still regarding COPD, E23(35), conducted with 206 participants with a mean age of 73 years old, showed an important development of exercise capacity ( 6 months) $(p<0.001)$, as well as a significant increase in the mean walking distance $(+17 \%)$. A benefit for pulmonary functions was also identified ( $p<0.001$ ), as well as an improvement in the mean forced expiratory volume in $1 \mathrm{~s}(+11 \%)^{(35)}$.

Finally, E28(40), conducted with patients undergoing hemodialysis ( $n=172$ ) with a mean age of 57 years old, revealed that, for the intervention group (6 months), fatigue was lower after 8 weeks of practice, with a significant decrease compared to the control group ( $p=0.005)$. In addition, the research identified the benefit of Qigong for this audience in terms of strengthening muscles, developing psychological function, and reducing stress ${ }^{(40)}$. 


\section{Discussion}

The use of Qigong in the health network is revealed as a practice capable of promoting health, in addition to meeting prevention, which can be confirmed based on the positive results demonstrated in this study. That said, it is necessary to encourage studies focusing on the results of Qigong, considering prevention and health promotion, since most research studies seek to investigate people with established diseases.

Several research studies on the subject also indicated improvements in breathing, circulation, relaxation, and functions related to cognition due to the practice of Qigong, similarly to the findings of this study ${ }^{(41-43)}$. There was also evidence capable of positively associating the practice with the management of risk factors related to cardiovascular diseases, that is, Qigong is relevant to promote health and prevent illnesses for adults and for the elderly.

COPD patients, mostly elderly, also found benefits from the practice of Qigong regarding pulmonary function, functional capacity, quality of life, and reduced fatigue. Such results are in line with another SR on the relationship between Qigong and COPD(41) with regard to the effects of therapy through breathing exercises techniques stimulated in the elderly, which projects great importance for planning the pulmonary rehabilitation of this population by the therapy.

Likewise, in this study, the practice had positive psychosocial results in elderly people, in line with related research studies, with similar results evidenced(44-46). A number of studies on the improvement of depression in adults and the elderly by Qigong associate this result with the reduction of stress-related signals received by the limbic system, in the hippocampus and in the amygdala, in view of the connection between mind/attention with a confirmed focus through therapeutic practice, which consequently demonstrates having an effect on the secretion of the hormone responsible for releasing corticotrophin from the hypothalamus and, as well as from that adrenocorticotrophic (ACTH) by the hypophysis ${ }^{(47-48)}$.

As for analgesic effects, pain was one of the important outcomes investigated by the studies, with the literature showing that the therapy can enhance the level of tolerance and perception of pain, especially in adults. In this way, a relevant endogenous release of pain control is related to the practice of Qigong in the studies(49-50). The effects of Qigong with regard to the pituitary-hypothalamus-adrenal axis, play an important role in the pathophysiology of fibromyalgia(49,51), which makes it relevant to the recommendation and employment in the search for rehabilitating adults and the elderly.
As for Parkinson's disease, studies in the area are in line with the results presented in this SR, proving that regular exercise practice, as proposed by Qigong, is beneficial for the rehabilitation of these patients, as it brings physical benefits, as well as a reduced chance that elderly people will suffer falls ${ }^{(52)}$.

With regard to the effects on oncology, a prospective longitudinal research has shown that it is even possible to consider the practice, inserted in the lifestyle, as protective with regard to the reduction of deaths due to neoplasms, by stimulating the immune system and controlling the inflammatory response related to the disease ${ }^{(53)}$.

It is also noted, in the research considered, an increase in the duration and intensity of the positive results of Qigong, proportional to the quantity practiced. This, therefore, needs to be considered to recommend engaging in research studies that aim to investigate the results of this practice for health. Therefore, an intervention protocol of at least four weeks is recommended, based on the results found in this SR.

Qigong is based on the development of selfknowledge, making its practitioner active and capable of preventing and curing diseases throughout life. Thus, Qigong is shown as a mind-body exercise modality that can be easily practiced by adults and very beneficial in the long term, as shown in the results of this study.

Through the critical evaluation conducted, it was possible to verify a high risk of bias in the research blinding domains, since this was impossible, and there was a probability of influencing the evaluation of the results, which lacked adequate control or, therefore, a clear description of the protocol and analysis(54).

It is recommended to carry out new randomized clinical trials with a high level of methodology focusing on this research subject. In addition, in order to assess the practice of Qigong, longitudinal research studies involving healthy people are necessary to compose the baseline.

\section{Conclusion}

It is possible to understand the physiological results from the practice of Qigong through the scientific evidence identified and submitted to evaluation, which makes this study of great contribution, since it brings a synthesis of the production regarding the use of an integrative and complementary practice in health, based on the most relevant scientific findings available.

The SR revealed the beneficial application of Qigong in the promotion, prevention, and rehabilitation of diseases and physiological disorders in adults and 
the elderly, such as: cancer; fibromyalgia; Parkinson's disease; COPD; Burnout; stress; social isolation; chronic low back pain; cervical pain; buzz; osteoarthritis; fatigue; depression; and cardiovascular diseases. This reinforces the need to strengthen the use of PICs, such as the Qigong, in health care with a view to ensuring comprehensiveness and to improving the health care assistance offered to adults and elderly individuals.

\section{References}

1. Assis WC, Britto FR, Vieira LO, Santos ES, Boery RNSO, Duarte CS. New forms of care through integrative practices in the Brazilian Unified Health System. Rev Bras Promoç Saúde. 2018;31(2):1-6. doi: http://dx.doi. org/10.5020/18061230.2018.7575.

2. Silva LB, Lima IC, Bastos RA. Complementary and integrative therapies: knowledge and use by nursing teachers in a public institution. Rev Saúde Col UEFS. 2015;5(1):40-5. doi: http://dx.doi.org/10.13102/ rscdauefs.v5i1.1008

3. Carvalho JLS, Nóbrega MPSS. Complementary therapies as resources for mental health in Primary Health Care. Rev Gaúcha Enferm. 2017;38(4):e2017-0014. doi: https://doi.org/10.1590/1983-1447.2017.04.2017-0014 4. Sousa LA, Barros NF. Integrative and Complementary Practices in the Unified Health System: progresses and challenges. Rev. Latino-Am. Enfermagem. 2018;26:e3041. doi: http://dx.doi.org/10.1590/15188345.2854 .3041

5. Dacal MPO, Silva IS. Impacts of integrative and complementary practices on the health of chronic patients. Saúde Debate. 2018;42(118):724-35. doi: 10.1590/0103-1104201811815

6. Matos LC, Sousa CM, Gonçalves M, Gabriel J, Machado J, Greten HJ. Qigong as a traditional vegetative biofeedback therapy: long-term conditioning of physiological mindbody effects. BioMed Res Int. 2015;53178:6. doi: http://dx.doi.org/10.1155/2015/531789

7. Doolen J. Meta-Analysis, systematic, and integrative reviews: an overview. Clin. Simul. Nurs. 2017;13(1):2830. doi: https://doi.org/10.1016/j.ecns.2016.10.003

8. Liberati A, Altman DG, Tetzlaff J, Mulrow C, Gotzsche PC, Loaniddis JPA, et al. The PRISMA statement for reporting systematic reviews and meta-analyses of studies that evaluate healthcare interventions: explanation and elaboration. BMJ. 2009;339:b2700. doi: https://doi.org/10.1136/bmj.b2700

9. Joanna Briggs Institute. Reviewers' manual 2014. Adelaide: University of Adelaide, Joanna Briggs Institute; 2014. [Internet]. [cited Oct 16, 2018]. Available from: http://joannabriggs.org/assets/docs/ sumari/reviewersmanual-2014.pdf
10. Moher D, Hopewell S, Schulz KF, Montori V, Gotzsche PC, Devereaux PJ, et a. Consolidated Standards of Reporting Trials Group. CONSORT 2010 explanation and elaboration: updated guidelines for reporting parallel group randomised trials. J Clin Epidemiol. 2010;63(8):e1-37. doi: https://doi.org/10.1016/j. jclinepi.2010.03.004

11. Polit DF, Beck CT. Fundamentos de pesquisa em enfermagem: avaliação de evidências para a prática de Enfermagem. 9ed. Porto Alegre: Artmed; 2018.

12. Higgins JPT, Altman DG. Assessing risk of bias in included studies. In: Higgins JPT, Green S, editors. Cochrane handbook for systematic reviews of interventions. Version 5.1.0 [updated March 2011]. The Cochrane Collaboration. [Internet]. 2011. [cited 2019 Jan, 22]. Available from: http://handbook-5-1. cochrane.org/

13. Larkey LK, Roe DJ, Smith L, Millstine D. Exploratory outcome assessment of Qigong/Tai Chi Easy on breast cancer suvivors. Complement Ther Med. 2016;29:196203. doi: 10.1016/j.ctim.2016.10.006

14. Xiao CM, Zhuang YC. Effect of health Baduanjin Qigong for mild to moderate Parkinson's disease. Geriatr Gerontol Int. 2016;16(8):911-9. doi: 10.1111/ggi.12571 15. Larkey LK, Roe DJ, Weihs KL, Jahnke R, Lopez AM, Rogers CE et al. Randomized controlled trial of Qigong/ Tai Chi Easy on cancer-related fatigue in breast cancer. Ann Behav Med. 2015;49(2):165-76. doi: 10.1007/ s12160-014-9645-4

16. Teut M, Knilli J, Daus D, Roll S, Witt CM. Qigong or Yoga Versus No Intervention in Older Adults With Chronic Low Back Pain: a Randomized Controlled Trial. J Pain. 2016;17(7):796-805. doi: 10.1016/j. jpain.2016.03.003

17. Blodt S, Pach D, Kaster T, Ludtke R, Icke $K$, Reisshauer $A$ et al. Qigong versus exercise therapy for chronic low back pain in adults: a randomized controlled non-inferiority trial. Eur J Pain. 2015;19(1):123-31. doi: 10.1002/ejp.529

18. Xiao DL, Hong ZJ, Bobby HPN, Yi HG, Yun CW, Gan L. Therapeutic Effects of Qigong in Patients with COPD: a Randomized Controlled Trial. Hong Kong J Occup Th. 2012;22(1):38-46. doi: https://doi.org/10.1016/j. hkjot.2012.06.002

19. Stenlund T, Birgander LS, Lindahl B, Nilsson $L$, Ahlgren C. Effects of Qigong in patients with burnout: a randomized controlled trial. J Rehabil Med. 2009;41(9):761-7. doi: 10.2340/16501977-0417

20. Ng BH, Tsang HW, Jones AY, So CT, Mok TY. Functional and Psychosocial Effects of Health Qigong in Patients with COPD: a Randomized Controlled Trial. J Altern Complement Med. 2011;17(3):243-51. doi: 10.1089/acm.2010.0215 
21. Hung HM, Yeh $\mathrm{SH}$, Chen $\mathrm{CH}$. Effects of Qigong Exercise on Biomarkers and Mental and Physical Health in Adults With at Least One Risk Factor for Coronary Artery Disease. Biol Res Nurs. 2016;18(3):264-73. doi: $10.1177 / 1099800415617017$

22. Hwang EY, Chung SY, Cho JH, Song MY, Kim $\mathrm{S}$, Kin JW. Effects of a Brief Qigong-based Stress Reduction Program (BQSRP) in a distressed Korean population: a randomized trial. BMC Complement Altern Med. 2013;13:113. doi: 10.1186/1472-6882-13-113

23. Tsang HW, Tsang WW, Jones AY, Fung KM, Chan AH, Chan EP et al. Psycho-physical and neurophysiological effects of Qigong on depressed elders with chronic illness. Aging Ment Health. 2013;17(3):336-48. doi: 10.1080/13607863.2012.732035

24. Lynch M, Sawynok J, Hiew C, Marcon D. A randomized controlled trial of Qigong for fibromyalgia. Arthritis Res Ther. 2012;14(4):R178. doi: 10.1186/ar3931

25. Ho RT, Chan JS, Wang CW, Lau BW, So KF, Yuen LP, et al. A Randomized Controlled Trial of Qigong Exercise on Fatigue Symptoms, Functioning, and Telomerase Activity in Persons with Chronic Fatigue or Chronic Fatigue Syndrome. Ann Behav Med. 2012;44(2): 160-70. doi: 10.1007/s12160-012-9381-6

26. Chan AW, Lee A, Suen LK, Tam WW. Tai chi Qigong improves lung functions and activity tolerance in COPD clients: a single blind, randomized controlled trial. Complement Ther Med. 2011;19(1):3-11. doi: 10.1016/j.ctim.2010.12.007

27. Rendant $D$, Pach $D$, Ludtke R, Reisshauer A, Mietzner A, Willch SN, et al. Qigong Versus Exercise Versus No Therapy for Patients With Chronic Neck Pain : a randomized controlled trial. Spine (Phila Pa 1976). 2011;36(6): 419-27. doi: 10.1097/BRS.0b013e3181d51fca

28. Biesinger E, Kipman U, Schatz S, Langguth B. Qigong for the treatment of tinnitus: a prospective randomized controlled study. J Psychosom Res. 2010;69(3):299-304. doi: 10.1016/j.jpsychores.2010.04.013

29. von Trott $P$, Wiedemann AM, Lüdtke $R$, Reishauer A, Willich SN, Witt CM. Qigong and exercise therapy for elderly patients with chronic neck pain (QIBANE): a randomized controlled study. J Pain. 2009;10(5): 501-8. doi: 10.1016/j.jpain.2008.11.004

30. Lee HJ, Park HJ, Chae Y, Kim SY, Kim SN, Kim ST, et al. Tai Chi Qigong for the quality of life of patients with knee osteoarthritis: a pilot, randomized, waiting list controlled trial. Clin Rehabil. 2009;23(6):504-11. doi: $10.1177 / 0269215508101746$

31. Haak T, Scott B. The effect of Qigong on Fibromyalgia (FMS): a controlled randomized study. Disabil Rehabil. 2008;30(8):625-33. doi: $10.1080 / 09638280701400540$
32. McQuade JL, Prinsloo S, Chang DZ, Spelman A, Wei Q, Basen-Enggist K, et al. Qigong/tai chi for sleep and fatigue in prostate cancer patients undergoing radiotherapy: a randomized controlled trial. Psychooncology. 2017;26(11):1936-43. doi: 10.1002/ pon.4256

33. Fong SS, Ng SS, Lee HW, Pang MY, Luk WS, Chung JW, et al. The Effects of a 6-Month Tai Chi Qigong Training Program on Temporomandibular, Cervical, and Shoulder Joint Mobility and Sleep Problems in Nasopharyngeal Cancer Survivors. Integr Cancer Ther. 2015;14(1): 16-25. doi: 10.1177/1534735414556508

34. Yeh ML, Chung YC. A randomized controlled trial of qigong on fatigue and sleep quality for non-Hodgkin's lymphoma patients undergoing chemotherapy. Eur J Oncol Nurs. 2016;23:81-6. doi: 10.1016/j. ejon.2016.05.003

35. Chan AW, Lee A, Lee DT, Suen LK, Tam WW, Chair $S Y$, et al. The sustaining effects of Tai chi Qigong on physiological health for COPD patients: a randomized controlled trial. Complement Ther Med. 2013;21(6): 585-94. doi: 10.1016/j.ctim.2013.09.008

36. Chan AWK, Yu DSF, Choi KC. Effects of tai chi qigong on psychosocial well-being among hidden elderly, using elderly neighborhood volunteer approach: a pilot randomized controlled trial. Clin Interv Aging. 2017;12:85-96. doi: 10.2147/CIA.S124604

37. Chuang TY, Yeh ML, Chung YC. A nurse facilitated mind-body interactive exercise (Chan-Chuang qigong) improves the health status of non-Hodgkin Iymphoma patients receiving chemotherapy: Randomised controlled trial. Int J Nurs Stud. 2017;69:25-33. doi: 10.1016/j. ijnurstu.2017.01.004

38. Liu P, You J, Loo WTY, Sun Y, He Y, Sit $H$, et al. The efficacy of Guolin-Qigong on the body-mind health of Chinese women with breast cancer: a randomized controlled trial. Qual Life Res. 2017;26(9):2321-31. doi: 10.1007/s11136-017-1576-7

39. Phattharasupharerk S, Purepong N, Eksakulkla S, Siriphorn A. Effects of Qigong practice in office workers with chronic non-specific low back pain: a randomized control trial. J Bodyw Mov Ther. 2018;23(2):375-81. doi: https://doi.org/10.1016/j.jbmt.2018.02.004 40. Wu CY, Han HM, Huang MC, Chen YM, Yu MP, Weng LC. Effect of qigong training on fatigue in haemodialysis patients: a non-randomized controlled trial. Complement Ther Med. 2014;22(2):244-50. doi: 10.1016/j.ctim.2014.01.004

41. Lottermann PC, Sousa CA, Liz CM. Exercise programs for people with COPD: A systematic review. Arq Cienc Saúde UNIPAR. 2017 [cited Aug 16, 2018];21(1):65-75. Available from: http://www.revistas.unipar.br/index. php/saude/article/view/5340/3398 
42. Hartley L, Lee MS, Kwong JSW, Flowers N, Todkill $D$, Ernst $E$, et al. Qigong for the primary prevention of cardiovascular disease (Review). Cochrane Database Syst Rev. 2015;6(CD010390):1-46. doi: 10.1002/14651858. CD010390.pub2

43. Xiong $X$, Wang $P$, Li X, Zhang Y. Qigong for hypertension: a systematic review. Medicine. 2015;94(1):e352. doi: 10.1097/MD.0000000000000352

44. Galvanese ATC, Barros NF, Oliveira AFPL. Contributions and challenges associated with bodily practices and meditation for health promotion in the public primary care system in the city of São Paulo, Brazil. Cad Saúde Pública. 2017;33(12):e00122016. doi: 10.1590/0102-311X00122016

45. Gil EM, López-Arza MVG. Systematic review about the effects of Qigong therapeutic exercise on balance. Altern Integr Med. 2017;6(1):1000236. doi: 10.4172/2327-5162.1000236

46. Chang $P$, Knobf MT, Funk M, Oh B. Feasibility and acceptabiliy of Qigong exercise in community-dwelling older adults in the United States. J Altern Complement Med. 2018;24(1):48-54. doi: 10.1089/acm.2017.0096

47. Chang P, Knobf MT, Oh B, Funk M. Physical and psychological effects of Qigong exercsie in communitydwelling older adults: An exploratory study. Geriatr Nurs. 2018;39(1):88-94. doi: https://doi.org/10.1016/j. gerinurse.2017.07.004

48. Jiang D, Kong WJ, Jiang J. The role of Tai Chi in mental health management - lessons learned from clinical trials. Rev Recent Clin Trials. 2016;11(4): 324-32. doi: 10.2174/1574887111666160729100829

49. Sawynok J. Qigong and Chronic Pain: Three Cases of Pain Resolution, Other Health Benefits and Improved Vision with Long-term Practice of Qigong. Fibrom Open Access. 2016 [cited Dec 12, 2018];1(2):1000111. Available from: https://www.omicsonline.org/openaccess/qigong-and-chronic-pain-three-cases-of-painresolution-other-health-benefitsand-improved-visionwith-longterm-practice-of-qigong-. php?aid=82025 50. Girard J, Girard A. The effects of qigong on neck pain: a systematic review. Complement Ther Clin Pract. 2019;34:23-9. doi: https://doi.org/10.1016/j. ctcp. 2018.10.013
51. Sawynok J, Lynch ME. Qigong and fibromyalgia circa 2017. Medicines (Basel). 2017;4(2):37. doi: 10.3390/ medicines 4020037

52. Zou L, Sasaki JE, Wang H, Xiao Z, Fang Q, Zhang M. A Systematic Review and Meta-Analysis Baduanjin Qigong for Health Benefits: Randomized Controlled Trials. Evid Based Complement Alternat Med. 2017;2017:17. doi: https://doi.org/10.1155/2017/4548706

53. Khattar E, Kumar P, Liu CY, Akincilar SC, Raju A, Lakshmanan $M$, et al. Telomerase reverse transcriptase promotes cancer cell proliferation by augmenting tRNA expression. J Clin Investig. 2016;126:4045-60. doi: 10.1172/JCI86042

54. Chang PS, Chao AM, Jang M, Lu YYF. Intervention fidelity in Qigong randomized controlled trials: a method review. Geriatr Nurs. 2019;40(1):84-90. doi: https:// doi.org/10.1016/j.gerinurse.2018.07.001 Creative Commons (CC BY). 